\title{
Futuremakers: Play and Festivities in the Park
}

Alessandro Columbano

SHORT PAPER FOR ARCHITECTURE AND CULTURE 6_3

\section{Author contact details:}

Senior Lecturer, Birmingham City University

Alessandro.columbano@bcu.ac.uk

+44(0)1213315857

\section{Author biography:}

Alessandro Columbano is a senior lecturer at the Birmingham School of Architecture and Design. He co-established the Collaborative Laboratory (Co.LAB), an organization within the school that integrates teaching with practice through live projects, staff research/design and external consultancy. As anviere, a self-chosen design guise, he has developed a portfolio of site-specific installations and artworks commenting on the subversive qualities of our physical environments.

\footnotetext{
Abstract:

This case study reflects on Futuremakers, a summer long festival on the theme of "play, make, build" held at the Midlands Arts Centre, Birmingham, UK. Set in a municipal park, the event brought local community groups together with creative practitioners through making visual work and discussing stories of local heritage, representing these findings in a curated gallery context. The reflections draw out an understanding of the impact of creative acts - how they can help redraw perceived boundaries between public and private space, and redefine ideas about how and where art can be generated.
}

Keywords: Birmingham; play; festivals; art practice; Cannon Hill Park

\section{Figure Caption:}

Children participating in one of the maker's workshops, developing their own stories and memories of the park through creative play (top). All the structures and artworks 
generated over the summer were presented at a public event at the end of the festival (bottom). Photographs by the author.

(to occupy the usually blank left-hand page, opposite the first page of the article).

\section{Futuremakers: Play and Festivities in the Park}

\section{Name of the Curated Festival or Event:}

Futuremakers: Play and Festivities in the Park

\section{Location and Date}

Midlands Arts Centre (MAC), Cannon Hill Park, Birmingham, UK. Summer 2017.

\section{Description}

Futuremakers was a participatory arts event that engaged a public audience to "play, make, build" over a period of eight weeks, culminating in a final event, the "Big Review." It was festival-like in its program structure and in the celebration of local contributions. Run at the Midlands Arts Centre (MAC), Birmingham, it was intended to explore heritage and community through creative making. The MAC is in Cannon Hill Park, a picturesque Victorian municipal park in South Birmingham that plays a prominent role in events for residents, artists, and community groups. The park regularly hosts formal themed festivals - religious or seasonal celebrations - as well as informal gatherings at the Victorian bathing ponds that come with their own rituals of how you enjoy and participate in a public space. ${ }^{1}$

Futuremakers sought to establish a creative environment to learn about local history by working with invited makers who occupied the institution for two weeks at a time: Dual Works, whose primary discipline is jewelry and object fabrication; Simon and Tom Bloor, visual artists who work with play spaces and storylines; and myself, acting on behalf of Co.LAB, with our experience of building architectural structures. In a series of workshops, the makers collaborated with groups of children to develop a series of "pavilions" to be set around the art center and park.

Exploratory play became the vehicle to recount fictional and collected stories of the park and the art center building. An expanding exhibition display in the gallery 
involved a particular kind of curating, as the children constantly created new art works and playful structures. The workshops took place roaming around the park, producing ideas through capturing spatial and visual qualities of the environment.

In the workshops, the maker-groups built structures with three different themes: conversations (Dual Works), the Story of Stones (Simon \& Tom Bloor) and light/shadows (Co.LAB). The project ended with a celebratory day-long event - the "Big Review." Work generated over the summer was presented in the gallery, this time understood as a theatre "in the round." Participants from all the previous workshops as well as members of the public were invited to view and play with the works displayed, and to build further structures. As they did so, conversations emerged between the makers, the children, and the wider community. The sharing of ideas and the collaborative making, wrapped in local stories, highlighted a simple communality centered on an arts institution and its particular setting. ${ }^{2}$

\section{Objectives}

The objective of Futuremakers was open up the idea of "play" between those in the design and creative professions and those in the community. The project aimed to do this by:

- encouraging the sharing of creative ideas about an area's local heritage and how they could be communicated in visual and spatial forms.

- $\quad$ asking how the public might celebrate creativity in an institutional setting.

- learning from past precedents for festival and "play" events, in particular those of Action Space, Sheffield and the Birmingham Arts Lab.

\section{Impacts / Reflections}

For the creative practitioners involved, children and adults, what was initially conceived as an event to promote public creativity through physical making became an ongoing process for all of us of using stories, connecting our making to some personal memory or historical fact about the art center and park. The combination of playfulness and seriousness involved in making the "art" allowed us all to take our understanding of the environment further. The makers' different practices generated works of varying scales that then facilitated conversations between different groups artists, general members of the public, participating children, gallery visitors. Through 
the aesthetic and physical value of the work we all came to recognize the value of the place. $^{3}$

One of the challenges for Futuremakers was to break down our preconceptions about what activities could occur where, particularly in terms of thinking about "inside" and "outside." We worked sometimes in the MAC building, sometimes in the public park outside, sometimes in workshop spaces, sometimes in the public gallery space. All of this re-drew the boundaries of where art is made and reflected on or where we engage in civic participation. The aspect of roaming in the park was reminiscent of previous play festivals like those of Birmingham Arts Lab in the 1970s, with its peripatetic performances around the suburban landscape of Newtown, their base in North Birmingham; jazz bands, theater groups and visual artists formed spontaneous gatherings with local children to generate and experience the making of art pieces away from established institutions. In his documentary "Action Space," about the group with the same name, founder Ken Turner articulates the concerns we also had: "we are an association working in the community interested in play, in education, developing art forms, specifically for the non-elite. They are the ones we are trying to reach." 4

Action Space, the Arts Lab, and Futuremakers all organized their festivities during official school holiday periods. I have fond memories of this time as a child, particularly of the seasonal recurrence of the summer break. I imagine that for the children involved, the Futuremakers project will build memories of play and place, connecting them with aesthetic pleasure in making, with aesthetic judgment. Creating a festive program of play allowed all participants to express such judgment, whether through making objects or through making conversation.

\section{References:}

Birmingham Mail, “Tulip Festival Was A Bloomin' Great Idea!”, Chinn, Carl https://www.birminghammail.co.uk/news/nostalgia/birmingham-tulip-festivalbloomin-great-7337900

Frieling, Rudolf. 2008. "Towards Participation in Art," in The Art of Participation: 1950 to Now, edited by Rudolf Frieling et al., 33-48. London: Thames and Hudson. 
Kidder, Paul. 2012. Gadamer for Architects. Abingdon: Routledge.

Huw Wahl, dir. 2016. Action Space. UK.

${ }^{1}$ Birmingham Mail , "Tulip Festival Was A Bloomin' Great Idea!", Carl Chinn, https://www.birminghammail.co.uk/news/nostalgia/birmingham-tulip-festival-bloomin-great$\underline{7337900}$ (accessed 18 $8^{\text {th }}$ April, 2018)

${ }^{2}$ Rudolf Frieling "Towards Participation in Art" in The Art of Participation: 1950 to Now, ed. Rudolf Frieling et al., (London: Thames \& Hudson, 2008), 48.

${ }^{3}$ Paul Kidder, Gadamer for Architects (Abingdon: Routledge, 2012)

${ }^{4}$ Huw Wahl, dir., Action Space (UK, 2016) 


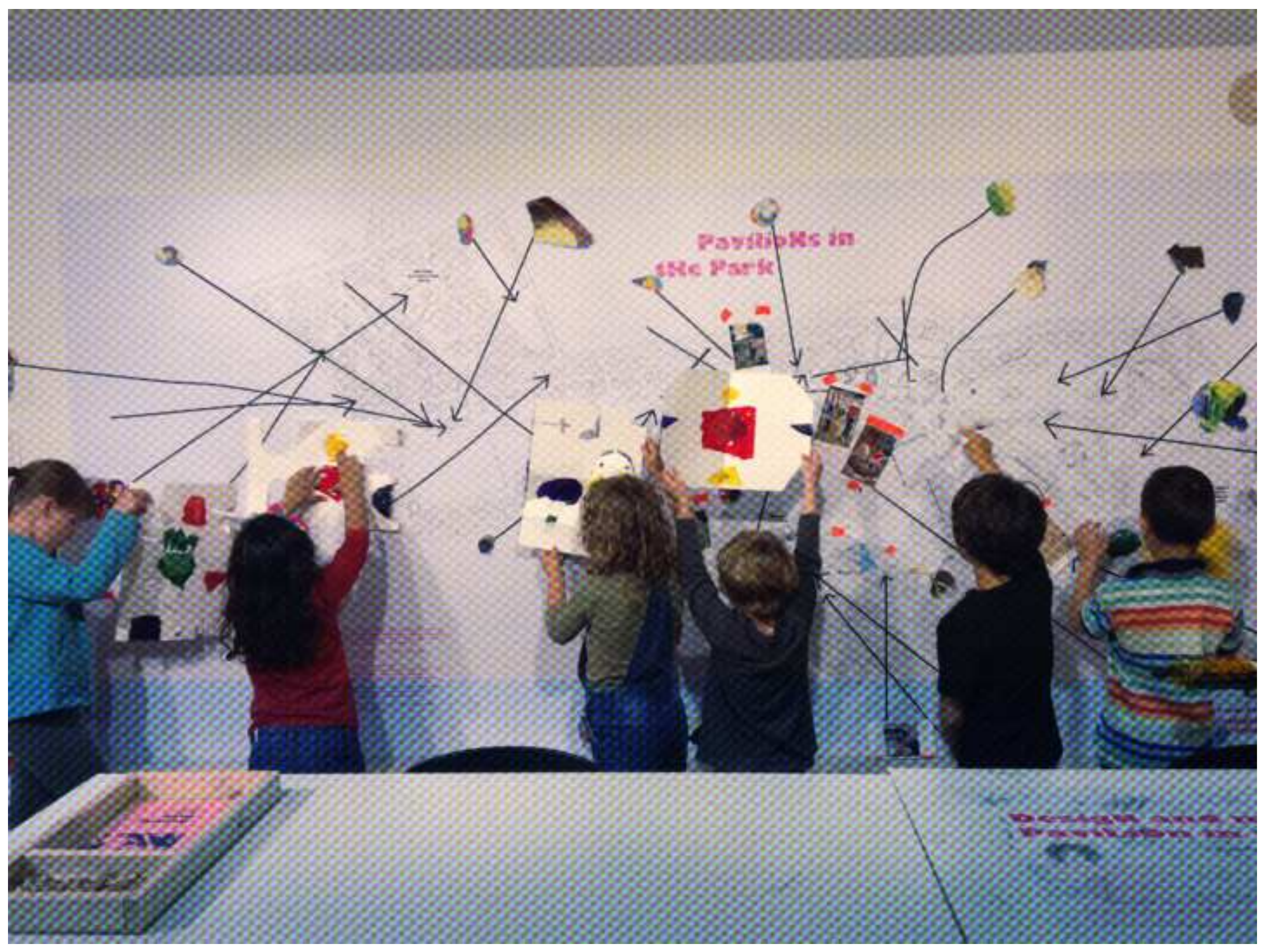




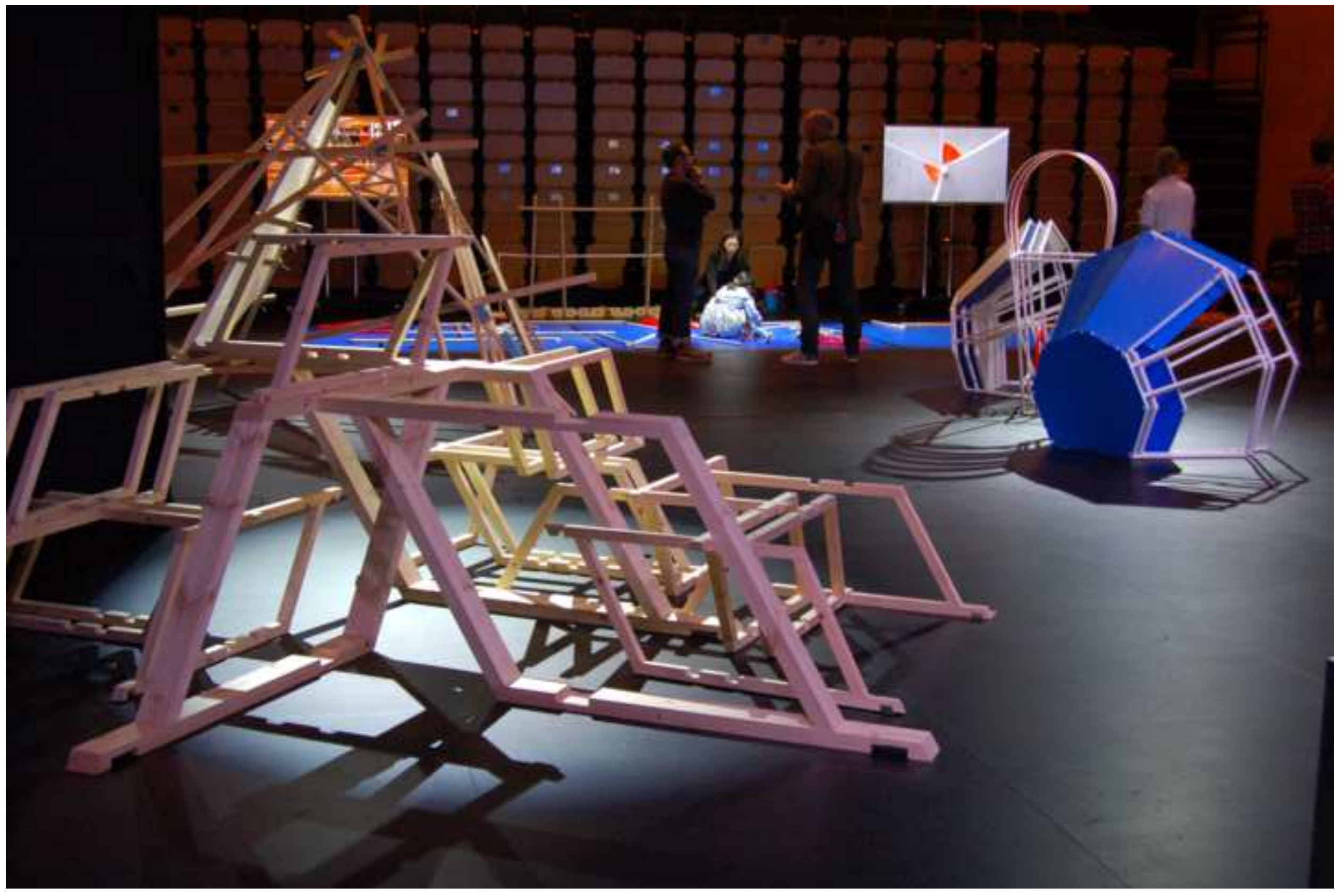



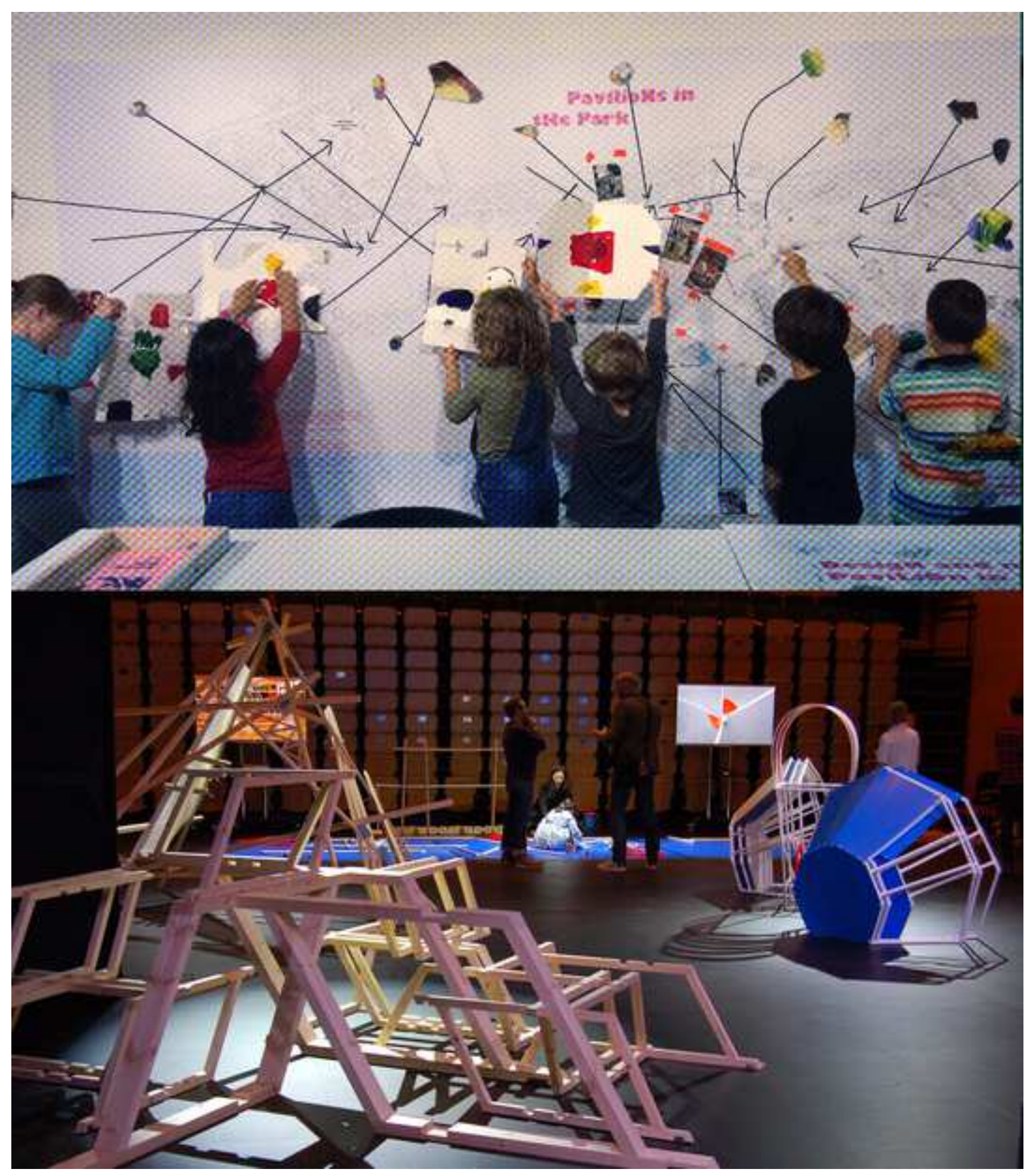

,

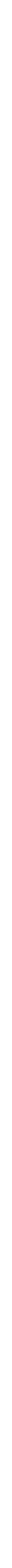

